\title{
The effects of age on gender stereotyping of computing
}

\author{
Gregory D. Preston \\ University of Newcastle \\ New South Wales \\ Australia
}

\begin{abstract}
This paper addresses the issue of gender stereotyping in relation to computers and computer based subjects found in Australian school students. The results reported here form part of an ongoing study into a range of computer access, attitude, and usage issues in relation to gender. This paper reports the stereotype views on computers and computer related activities of 200 school students aged from 9 to 18 . The data were collected using an instrument specifically developed for the study. The results were analyzed and applied to a causal model. The study generally found that computing was perceived as a male domain. However this was not consistent across the age groups under consideration. The developed causal model highlights the complexity of the variables affecting stereotyping, and specifically identifies 'modelling' and 'subject association' as having a direct relationship with the sextyping of computer activities.
\end{abstract}

Main conference themes: equity issues

Educational areas: primary education, secondary education

Study topics:

Secondary keywords: attitudes, culture 


\section{INTRODUCTION}

A plethora of studies conducted in the last ten years has reported gender based differences in relation to computing. Generally, these studies have reported higher levels of computer usage among males, especially in the areas of programming and game playing [1, 2]. Additionally, the consideration of access issues has yielded similar results. Males are more likely to own a computer, participate in formal and nonformal computer activities, and dominate time on available computing resources $[3,4]$. The net result of these phenomena being that males are significantly more likely to have had previous computing experience across a variety of computing applications at the end of their school years [5].

The studies which consider attitudes to computing, however, have reported less conclusive results. Numerous studies have reported that males have more positive attitudes towards computing, lower levels of computer anxiety, and perceive a greater relevance in computer related tasks. Alternatively, some studies have reported no significant differences in relation to these issues. The sample groups from these apparently conflicting studies contained subjects from a wide range of age groups and geographic regions. However, none of these studies suggested that females had more positive attitudes to computing than their male counterparts $[1,6]$.

A number of theories have been proposed to account for these results, including the interrelationship and complex nature of the variables under consideration [7]. However, one issue which has been widely supported in accounting for these data, is the general gender stereotyping of computers in society. In line with the complex nature of the variables involved in any form of social interaction, the issue of gender stereotyping is itself not unidimensional. Francis [6] outlined three strands of research concerning gender stereotyping of computing activities.

The first of these strands, in line with general usage and access data, suggests that computers are perceived as predominantly male devices. Within this strand some research supports the concept that both females and males share these views, while other studies have found that males are more likely to claim computing as a male domain and females are more likely to support equity positions.

The next strands of research attempt to account for stereotyping in different terms. The identification of a mismatch between general concepts of equity and individual performance, also known as the "We can, I can't paradox" has been postulated as an additional position held by females on this issue [8]. A study by Lage [9] is typical of the final strand, which cuts across the gender stereotyping issue. She considered estimates by 10-11 and 14-15 year olds on 
the social skills and characteristics of female "computer users". The results showed that these estimates were disparate for different chronological age groups within her sample group. For example, the 10-11 year old group had more positive attitudes to a female 'computer enthusiast' than their older counterparts.

The aim of the present study therefore is to further explore these issues in an Australian school setting. Specifically the following research questions were isolated:

1. Is there sex based stereotyping of computer based activities?

2. Are any differences in access, attitudes, and usage related to this sex based stereotyping?

3. Is there any appreciable change in the sex based stereotyping of students with age?

4. Is any such change consistent across the sexes?

\section{METHOD}

\section{Questionnaire}

The questionnaire established background data for the respondents as well as collecting information on students' access to computing resources at home and at school. Data were also collected on a number of groupings of potentially intervening variables, specifically: Experience, Access, Modelling and Association. Finally, data were collected on students' computing attitudes and perceptions of stereotyping. This was achieved using the Computer Attitude Scale [10], in conjunction with a sextyping scale developed for this project. The developed sextyping scale considered items relating to perceptions of achievement, occupational relevance and 'natural' talent. Typical of the scale items included were: "Girls like computing more than boys do" and "Boys are better at computing than girls are".

\section{The sample}

Data were collected from 200 students in eight schools. The schools were all drawn from a major regional centre in New South Wales, Australia. There were three Secondary schools and five Primary schools involved in the study. The 200 students were made up of 20 students from each of the academic years from Year 3 through to Year 12. Within each of these groups 10 of the students were female and 10 were male. The student questionnaires were administered during normal classroom lesson time and were part of a battery of 
tests administered at this time. All the instruments were administered by the researcher.

\section{Results}

A reliability test was conducted on the instrument to assess its validity. The reliability Cronbach alpha coefficient obtained for the sextyping scale developed was 0.8106 , which was considered satisfactory considering the small sample size. The impact of the intervening variables was also considerable. The four areas addressed were: Experience, Access, Modelling and Association.

\section{Experience}

The rate of in-school use is relatively high, with almost all students reporting that they had used a computer at school at least once. There was no significant difference between the sexes on this variable. In relation to the selection of computer studies, 80 of the High school students were undertaking 'computer studies' of some form. It was not possible for students attending a primary school to undertake computer studies as a discrete subject. Of those undertaking computer studies 42 were male and 38 female. However, considering mode of use, females were more likely to report that when sharing the computer they received an lesser share of computer time than males.

Likewise there was a number of differences between males and females when considering type of computer usage. Using the computer as a drawing tool was the most frequently reported use of the computer in secondary schools, while 'writing stories' was the most common primary application. Males exceeded females in all areas of computer use, with the exception of word processing (story writing).

As with the in-school usage there was a number of differences between males and females with respect to type of computer usage at home. Using computer games was the most frequently reported use of the computer across both sexes and all year groups. Again the only type of use where females exceeded males, was word processing (story writing).

\section{Access}

The first point to note is the large number of students who had access to home computers. The overall percentage of students with home computers in the pilot group was $76.5 \%$, with no significant differences between male and female ownership. The only variable which correlated with home computer ownership, was the socioeconomic status (SES) of the father, with a higher SES leading to an increased likelihood of home computer ownership $(p<0.05)$.

There was, however, a significant difference in the sex based location of these home computers. Fifty-two percent of the home computers was placed 
in identifiably 'male' locations, with only twenty-three percent in 'female' locations (significant at the $\mathrm{p}<0.01$ level).

\section{Association}

There was a clear link between sex and subject association in the data. There was a significant difference when the students perceptions of the associated subject were considered. Males were more likely to report that they liked a subject which they associated with computing ( $>>0.05)$. Females were less likely to have a strong association with the linked subject.

\section{Causal model}

The data collected were also analyzed in terms of a causal model. The model was applied to the data for each of the measures identified above. The analysis was conducted in two stages using multiple linear regression.The restricted model for the sex typing variable is shown in Figure 1.

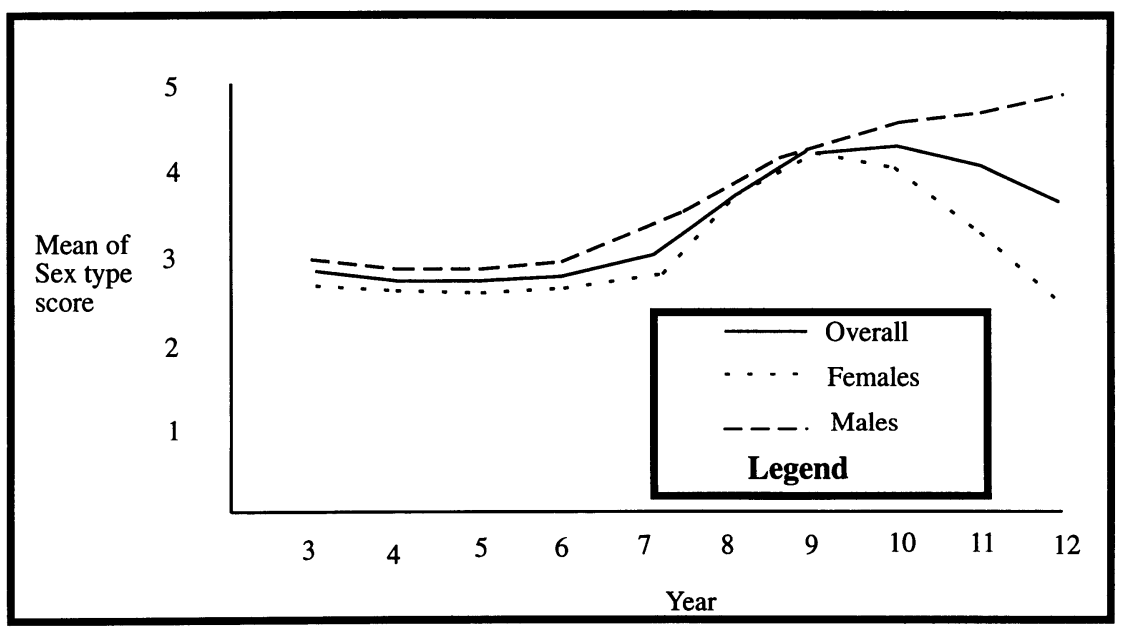

Fig. 1 Mean score on sex typing scale and academic year

As shown above, this analysis of the sex typing variable resulted in a number of significant paths, primarily from the modelling (role models) and association blocks. It is also important to note that sex was found to have a direct path to the sex typing variable, stressing the importance of these variables in relation to formation of stereotyping attitudes. The high $\mathrm{R}$-squared value further enhances this significance. 
The sextyping scale also correlated significantly with the academic year of the subject $(\mathrm{p}<0.01)$, with an increase in age leading to an increase in the sextyping of computer activities. This is represented diagrammatically in Figure 2, with a high score indicating that the age group perceived computing as a more male domain.

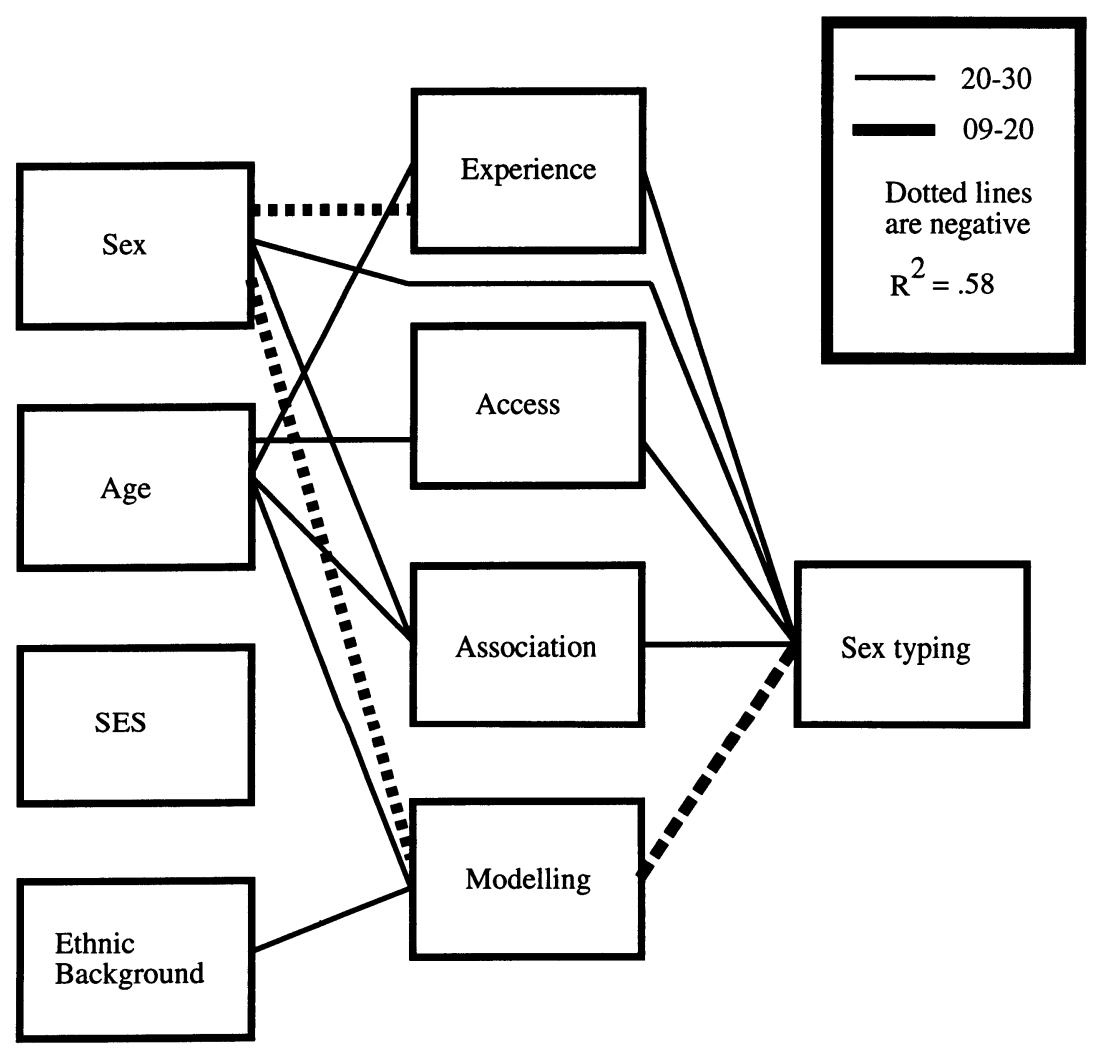

Fig. 2 Path diagrams of significant paths for the computer sex typing variable

It is interesting to note here that the males seem to begin perceiving computing as a male domain earlier than females, and that older students exhibit a greater variance in opinion on the sex typing issue. 


\section{CONCLUSION}

A number of preliminary conclusions emerged from consideration of the research questions posed in the study. It is clear that gender is an important issue in students' perception of stereotyping in relation to computing. In line with previous research, these data show that males and females were more likely to perceive computing as male domain [11]. The features which impacted significantly on the formation of this attitude being Modelling, Age and Association.

Additionally, these data highlight the changeable nature of the stereotyped attitudes. During the adolescent period both female and male perceptions of computer stereotyping undergo considerable change. Such change would appear to be congruous with the findings of Lage reported above. This can also be construed as a source of both hope and disappointment for those wishing to alter students perceptions in relation to computing. Hope, as the perceptions are clearly open to change, and disappointment owing to the nature of the change demonstrated in the sample group.

Further, the study appears to add weight to the proposition that the gender stereotyping issue requires a holistic approach [7]. The fact that males in this study began seeing the computer as a male domain prior to any change in the females' perceptions, is open to a number of interpretations. Perhaps the most plausible of these explanations would seem to be 'attitudinal aggression', with the males first claiming the devices and female attitudes then yielding. This extends the premise previously proposed, that females will yield control of physical devices to avoid confrontation and seek friendship, to the arena of attitude formation [12]. It is therefore clear that those who would construct gender stereotyping in relation to computing in terms of being a 'female problem' can draw no support from these data. Any intervention program must clearly address all students.

The study also offers some relevant information in relation to the timing of any such intervention program with the present population. In Australia, many of the existing intervention programs only commence when the attitudinal changes highlighted in this study already have begun. Further research is required to assess the impact of programs which commence at different points in relation to the attitudes held.

Finally, these data further support the view that stereotyping in relation to computing is a complex issue and generalization of previous findings to new populations is not necessarily valid. The variety and complexity of the significant paths within the causal model, combined with the fact that the model proposed is just one of a number which could be explored, highlight this. Further replication of this study is recommended to explore the findings 
described here, specifically in relation to the interaction between general attitudes and stereotyping, across different populations, and with larger sample sizes.

\section{REFERENCES}

1, Sutton, R. E., (1991) Equity and Computers in the Schools: A Decade of Research. Review of Educational Research 61 (4) pp. 475-503.

2. Chen M. (1986) Gender and Computers: The beneficial effects of experience on attitudes, Journal of Educational Computing Research 2 (3) pp. 265-281.

3. Miura, I.T. and Hess, R.D. (1984) Enrolment differences in computer camps and summer classes. The Computing Teacher 11 (8) p. 22.

4. Nolan, P.C.J., McKinnon, D.H. and Soler, J. (1992) Computer in Education: Achieving equitable access and use. Journal of Research on Computing in Education 24 (3) pp. 299-314.

5. Clarke, V.A. and Chambers, S.M. (1989) Gender-based factors in computing enrolments and achievement. Journal of Educational Computing Research 5 (4) pp. 409-429.

6. Francis, L.J. (1994) The relationship between computer related attitudes and gender stereotyping of computer use, Computers in Education 22 (4) pp. 283-289.

7. Kay, R.H. (1992) Understanding Gender Biases in Computer-Related Behavior: Are we using the wrong metaphor? in Martin, C.D. and MurchieBeyma, E. (eds) In Search of Gender Free Paradigms for Computer Science Education, ISTE Eugene, Oregon, pp. 9-14.

8. Makrakis, V. (1993) Gender and computing in schools in Japan: The "We can, I can't" paradox. Computers in Education 20 (2) pp. 191-198.

9. Lage, E. (1991) Boys, girls and microcomputing. European Journal of Psychology in Education 6, pp. 29-44 
10. Gressard, C.P., and Loyd, B.H. (1986) Validation studies of a new computer attitude scale. Association for Educational Data Systems Journal 18 (4) pp. 295-301.

11. Preston G.D., and Au, W.K. (1989) Gender Differences in computer access of secondary students, in Sutton, D., Hands On: The proceedings of the 7th annual conference of the NSW. Computer Education group, pp. 219-231.

12. Boss, J. (1982) Sexism among the micros. The Computing Teacher 9 (5) pp. 55-57. 